\title{
The Moderating Effects of Experience and Training on Students' Use of a Learning Management System
}

\author{
Ahmed Alshehri, Malcolm Rutter, and Sally Smith
}

\begin{abstract}
E-learning systems have become progressively more vital for universities, schools and other organisations to provide informational content and instructive resources. Incorporation of technology in learning and teaching environment is no longer an option, but a necessity. Still, the challenge for educational institutions is how to attract learners to their e-learning services. The study utilised an extended Unified Theory of Acceptance and Use of Technology (UTAUT) model to investigate empirically the variables that influenced the students use of a Learning Management System (LMS) in Saudi tertiary education. The focus of this study is the impact of demographic characteristics of experience and training on the students' use of the LMS. Based on survey data from 605 respondents, Partial Least Squares Structural Equation Modelling (PLS-SEM) in conjunction with multigroup analysis techniques were employed to assess the model. The results showed that experience moderated the relationship between behavioural intention and actual use, information quality and behavioural intention as well as social influence and actual use. Whereas only the association of information quality on performance expectancy was moderated by the training variable. These findings may contribute to a deeper understanding of e-learning students' adoption behaviour. In light of these findings, the recommendations along with the study's' limitations were communicated.
\end{abstract}

Index Terms-e-Learning systems, PLS-SEM, moderators technology acceptance, UTAUT.

\section{INTRODUCTION}

Technological advancements have progressed substantially in the past decades. While the progress of technological innovations is continuing, the transfer of these advances into education has become a current issue. The successful experience of e-services around the world has led to the redefinition of the role of educational institutions. That is through the adoption of e-learning services and techniques. The goal is to create a lifelong learning environment with cost-efficient, flexible and accessible education regardless of geographic and time boundaries. Among the diverse educational technologies, the LMS is a common e-delivery medium within academic institutions, possessing robust capabilities for delivering online courses in distance learning as well as augmenting on-campus courses in blended learning [1]. Educational institutions

Manuscript received March 29, 2020; revised June 20, 2020. This research was financially supported by the Saudi Arabian Ministry of Education.

A. Alshehri is with Albaha University, Albaha, Saudi Arabia. He is also with Edinburgh Napier University, Edinburgh, United Kingdom (email: a.alyehyawi@bu.edu.sa)

M. Rutter and S. Smith are with School of Computing, Edinburgh Napier University, Edinburgh, United Kingdom (e-mail m.rutter@napier.ac.uk, s.smith@napier.ac.uk). implement LMSs such as the Blackboard system to administer their curricula with various types of functionalities, such as announcements, discussion board, online assessment and document sharing [2], [3].

In Saudi Arabia, most universities are equipped with the Blackboard system as the main application for learning and teaching. A more recent statistic indicated that the Blackboard system is by far the most prevalent LMS in Saudi higher education used by $90 \%$ of kingdom public universities [4]. Nonetheless, having access to an LMS does not necessarily mean that effective learning has occurred [5]. Despite the apparent usefulness, the issue of effective use of an LMS is an intriguing one [5]. In fact, the decisions about the integration of LMS into universities are often at a higher management level. Yet, it is the individual adoption patterns that illustrate the successful implementation [6]. Salloum \& Shaalan [7] reported that developing countries have failed, fully or partially, to implement LMSs effectively. A lack of utilization of these systems has been observed and the need to explore this challenge is still evident [7]-[9]. Therefore, understanding why students decide to use or reject an elearning system can create a more favourable environment for greater adoption, as well as helping to design strategies to promote acceptance.

To address this gap, the technology acceptance models and theories examine the individual and the choices that are made to accept or reject a particular system [6]. Venkatesh and colleagues [10] developed a Unified Theory of Acceptance and Use of Technology (UTAUT) model based on a comprehensive review of diverse theories for computer use predication. The model unifies the theoretical models in information system studies and integrates human and social constructs to form a unique extensive model [10]. The model established a unique measure with four essential constructs of user behavioural intention and usage, including Performance Expectancy (PE), Effort Expectancy (EE), Social Expectancy (SE) and necessary Facilitating Condition (FC). All these elements are direct determinants of user intention and behaviour [10].

Demographic characteristics such as age, experience, gender and voluntariness are posited to moderate the influence of the four key constructs on behavioural intentions [10]. The amalgamation of the core constructs and the moderating inputs has improved the predictive efficiency to $70 \%$ of the variance in behavioural intention to use technology [10]. Furthermore, the presence of demographics moderators in the UTAUT model has strengthened the model's power to explain technology acceptance and usage [10]. It has been established that users' individual differences, such as age, experience, training, can have an influence on the users' beliefs in using the system [11]. The 
moderators of gender, experience and training have been critical in using the LMS in Saudi Arabia [12]. It has been established that moderating factors have profound effects on user technology acceptance [13]. This not only contributes to the potential increase in the models' explanatory power but also leads to a better understanding of the dynamics of the user technology acceptance phenomenon [13].

From a methodological perspective, it is evident that the majority of structural equation models have not examined the moderating effects [14]. Many studies have failed to address whether there are significant differences across two or more groups of data [15]. The result interpretation from a single population sample can be misleading and may contribute to an invalid conclusion [15]. Moderator variables are considered important as specific variables are often expected to influence the relationships between the predictors and the outcomes [14], [16], [17].

This study attempts to extend the UTAUT model with six external variables and two demographic moderators. In particular, the proposed model measured the effects of the moderators LMS experience and given training on the students use of LMS in Saudi tertiary education.

\section{THEORETICAL MODEL}

The UTAUT model has been extended with six usability attributes to measure students' behavioural intention and actual use of an LMS in Saudi higher education. The selection of the UTAUT framework was due to its comprehensiveness and powerful explanatory power in the students' use of the e-learning system [7]. It is now well established from a variety of studies that usability attributes and user acceptance variables are essential to the diffusion of a given technology [18]. In this research, the UTAUT model was extended with six usability dimensions namely: system navigation, system learnability, visual design, information quality, instructional assessment and e-learning system interactivity. These six usability variables have been validated extensively in prior studies in the domain of usability, e-learning and educational technologies [19]-[24]. Along with that, the two moderators of students' LMS experience and training were posited to influence all the model relationships. In this endeavour, the focus is on the influence of the moderation effect of LMS experience and training on the model relationships. The proposed model is depicted in Fig. 1.

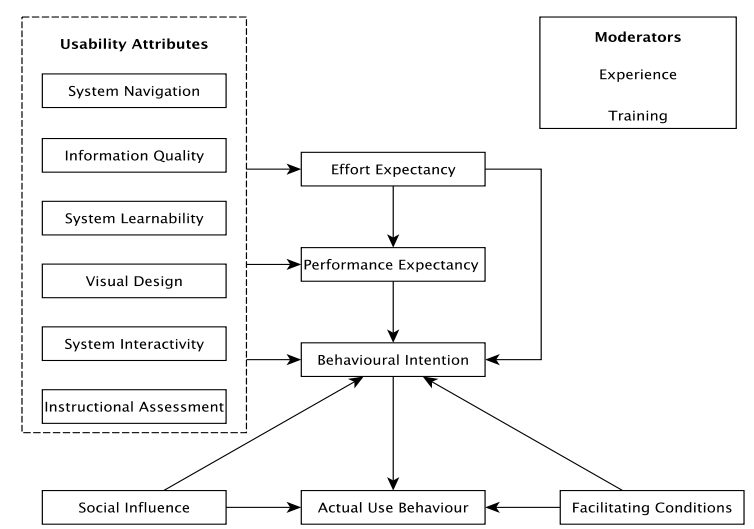

Fig. 1. The proposed model.

\section{A. Experience Moderating Effect}

The first moderating variable is LMS experience. Experience refers to the individuals' involvement with the system over a period of time [10]. It is measured by a number of years that students have been using an LMS [25]. It is an important moderating variable in IT adoption contexts as individuals' reactions toward an IT may change over time [26], [27]. In a study set out to compare the determinants of IT usage for experienced and inexperienced users, it was discovered that the inexperienced users placed a different emphasis on the determinants of usage and intention [27]. Extensive research has shown that the students' experience in the use of LMS can change the intention usage behaviour [28]. Perceptions of intention differed significantly between students with and without prior experience [28]. Recently, Zhang et al. [29] findings demonstrated the significant difference in the effect of usage experience, as a moderator, in the students' attitude and intention to use LMS. The intention in low-experienced users was influenced by information quality and perceived usefulness whereas for highly experienced users, the intention was influenced positively by information satisfaction, interaction satisfaction and perceived usefulness [29]. Consequently, this stimulus would affect students' intention and actual use of the targeted system. Furthermore, Venkatesh et al. [30] postulated that the experience will moderate the effect between behavioural intention and actual use behaviour and that will be stronger with less experienced users. In the Arab world, the previous student experience came as the most critical factor in the e-learning success model [31]. Drawn up for the earlier discussion, it is assumed that different factors within the model may have different influences on students' perceptions of performance expectancy and effort expectancy as well as on intention and usage, depending on the students' experience with the LMS. Since the experience variable has the potential to modify the model relationships, this study will postulate that the students experience of LMS moderates the interaction of the model variables.

$H_{1}$ : LMS experience will moderate all relationships in the proposed model.

\section{B. Training Moderating Effect}

The success of the e-learning system implementation depends primarily on training and professional development [12], [32], [33]. Individuals can benefit from many forms of training such as workshops, online tutorials, courses, and seminars [34]. Training programmes affect significantly the individuals' computer self-efficacy [35]. In this study, the training variable was measured by a number of training hours given to students. In a study set out to determine the effect of demographic characteristics on the acceptance and use of technology, the training determinant was found to be the most important driver of users perception of technological innovation [36]. The training can also boost the users' confidence with regard to the capability to learn and use of technology [36]. Besides, it was established that training promotes greater understanding, favourable attitudes, more frequent use, and more diverse use of applications [37]. Problems of using technology are likely to arise if users are not provided with adequate training [35] 
Data from several sources have concluded that the scarcity of training has been considered among the most significant barriers in the use of e-learning system services in Saudi higher education [12], [33]. The effect of training moderation is lacking in the IS/IT acceptance research especially in the Arab context [38]. In the study conducted by Asiri et al, [12], the individuals' characteristics of training was reported to be a critical factor that influenced the utilization of LMS in Saudi Arabia. Furthermore, the availability of training has a direct effect on individuals' beliefs of perceived usefulness and perceived ease of use, where the latter is affected the most by the training variable [38]. Likewise, in an investigation into LMS acceptance in Saudi tertiary education, Alshehri et al. [9] found that the majority of students had no previous training in the use of LMS $(64.3 \%)$ whereas a minority $(32.2 \%)$ reported some training (1-5 hours). The lack of training and the absence of administrative support was a major barrier to the integration of technology in higher education [39]. External variables such as system training can affect the user beliefs in using the system [11], [40]. Hu, Clark, \& Ma [41] compared the moderating effect of teachers' training on the Technology Acceptance Model (TAM) relationships. Several noticeable changes in TAM key acceptance drivers and their influence patterns or magnitudes were observed over the course of the training [41]. Therefore, the following hypothesis was proposed to investigate the effect of students' training.

$\mathrm{H}_{2}$ : Training will moderate all relationships in the proposed model.

\section{Methodology}

The target sample for this study was taken from students in Saudi higher education. The researcher targeted the students in Saudi higher education with geographically dispersed universities. Due to the large sample frame of Saudi students, a sampling technique was necessary. Hence, the study approaches this concern using a multi-stage cluster sampling technique as suggested by [42].

Quantitative research in the form of an online questionnaire-based survey was performed to test the hypotheses. The instrument was divided into three main sections. The first section included information about the respondents' characteristics. In this section, the students select the number of hours of provided training as well as the years of LMS experience. The second section is concerned with UTAUT constructs. This section comprises 25 positive statements divided into six subscales using a five-point Likert scale, based on LMS use in higher education. The last part elicits students' perception of the six usability variables, containing 31 positive statements.

Three thousand emails, providing a hyperlink the Webbased survey, were distributed to students in five public universities. Specifically, the online survey was employed to reach the wider population of the females' colleges as female students study in gender-segregated campuses. A total of $861(28 \%)$ were returned and $256(30 \%)$ questionnaires were incomplete and considered unusable due to the excessive missing data. Those instances had to be discarded before the process of data analysis. Besides, after the preliminary examination for outliers, normality and unengaged responses, 605 responses (20\% response rate) were used for data analysis. The results indicated that males represent $46.1 \%$ (279 participants) and females 53.9\% (326 participants).

\section{DATA ANALYSIS}

This study employed the Partial Least Squares Structural Equation Modelling (PLS-SEM) approach to test the measurement and structural model using SmartPLS 3 [43]. The multigroup analysis (MGA) technique was used to test the moderating effects. Many researchers emphasised the importance of using multigroup analysis using PLS-SEM technique, to analyse the effects of moderation across multiple relationships rather than standard moderation [14] [16], [44], [45].

\section{A. Measurement Model Assessment}

\section{1) Experience}

The experience moderator was examined based on a nominal scale. Therefore the refinement strategies were not required [46]. The data were divided into low and high experienced users. The first step of analysis is to ensure construct reliability and validity, including construct reliability and construct convergent and discriminant validity [44]. Cronbach's Alpha (CA) is the measure for the internal consistency; the degree to which responses are consistent across items within variable [47]. The Composite Reliability (CR) is a more conservative measure of internal consistency reliability where varying factor loadings are taken under consideration [17]. The items in the composite reliability are weighted based on the constructs' indicators loadings so the reliability is higher than Cronbach's alpha [48]. In this research, the researcher ran the PLS algorithm for both groups and found all the items' ranges were acceptable except one item (AU2 "I have been using Blackboard regularly in the past" $=0.50$ ) in the high experienced students' category, which did not conform to the standard factor reliability cut-off of .7 [46]. The researcher has decided to remove the AU2 indicator for both groups and re-estimate the model. The results of the PLS algorithm for students' e-learning experience is presented in Table I. As it can be observed from the data, for each construct, criteria of internal consistency reliability, composite reliability exceeded the threshold of 0.7 as suggested by [46], providing evidence of high reliability of the constructs. For the assessment of validity, all constructs in both groups have their Average Variance Extracted (AVE) greater than 0.5 as recommended by [46] and hence, convergent validity has been established.

TABLE I: THE MEASUREMENT MODEL ASSESSMENT FOR EXPERIENCE

\begin{tabular}{|c|c|c|c|c|c|c|}
\hline & \multicolumn{3}{|c|}{ High Experience } & \multicolumn{3}{c|}{ Low Experience } \\
\hline Construct & $\begin{array}{c}\text { CA }> \\
\mathbf{0 . 7}\end{array}$ & $\begin{array}{c}\mathbf{C R} \\
\mathbf{8 . 7}\end{array}$ & $\begin{array}{c}\text { AVE } \\
\mathbf{>} \mathbf{0 . 5}\end{array}$ & $\begin{array}{c}\text { CA } \\
\mathbf{0 . 7}\end{array}$ & $\begin{array}{c}\mathbf{C R} \\
\mathbf{8 . 7}\end{array}$ & $\begin{array}{c}\text { AVE } \\
\mathbf{0 . 5}\end{array}$ \\
\hline Actual Use (AU) & 0.79 & 0.88 & 0.71 & 0.77 & 0.87 & 0.69 \\
\hline $\begin{array}{c}\text { Behavioural } \\
\text { Intention (BI) }\end{array}$ & 0.90 & 0.95 & 0.81 & 0.91 & 0.95 & 0.82 \\
\hline $\begin{array}{c}\text { Performance } \\
\text { Expectancy (PE) }\end{array}$ & 0.81 & 0.87 & 0.64 & 0.88 & 0.92 & 0.74 \\
\hline $\begin{array}{c}\text { Social Influence } \\
\text { (SI) }\end{array}$ & 0.78 & 0.86 & 0.61 & 0.81 & 0.88 & 0.64 \\
\hline
\end{tabular}




\begin{tabular}{|c|c|c|c|c|c|c|}
\hline $\begin{array}{c}\text { Effort Expectancy } \\
\text { (EE) }\end{array}$ & 0.88 & 0.92 & 0.73 & 0.91 & 0.94 & 0.79 \\
\hline $\begin{array}{c}\text { Facilitating } \\
\text { Conditions (FC) }\end{array}$ & 0.79 & 0.85 & 0.53 & 0.80 & 0.86 & 0.56 \\
\hline $\begin{array}{c}\text { Instructional } \\
\text { Assessment (IA) }\end{array}$ & 0.87 & 0.90 & 0.61 & 0.91 & 0.94 & 0.73 \\
\hline $\begin{array}{c}\text { Information } \\
\text { Quality (IQ) }\end{array}$ & 0.91 & 0.95 & 0.77 & 0.91 & 0.95 & 0.78 \\
\hline $\begin{array}{c}\text { System } \\
\text { Learnability (SL) }\end{array}$ & 0.85 & 0.89 & 0.62 & 0.88 & 0.93 & 0.71 \\
\hline $\begin{array}{c}\text { System } \\
\text { Navigation (SN) }\end{array}$ & 0.84 & 0.89 & 0.61 & 0.85 & 0.89 & 0.63 \\
\hline $\begin{array}{c}\text { Visual Design } \\
\text { (VD) }\end{array}$ & 0.91 & 0.93 & 0.70 & 0.91 & 0.94 & 0.72 \\
\hline $\begin{array}{c}\text { E-learning System } \\
\text { Interactivity (ESI) }\end{array}$ & 0.86 & 0.90 & 0.70 & 0.91 & 0.93 & 0.78 \\
\hline
\end{tabular}

CA: Cronbach's alpha, CR: composite reliability, AVE: average variance extracted

The values of the Fornell-Larcker discriminant validity for lower and higher experienced students are shown in Table III. Using the Fornell-Larcker criterion [49], the constructs share more variance with its assigned indicators than with any other construct, hence discriminant validity has been established for both sub-samples. Therefore, the measurement model assessment was successful for both high and low-experienced groups.

\section{2) Training}

The population sample was divided into trained and untrained users. Trained users are those who received LMS training and untrained students are those who had no previous training in the use of LMS. The trained students constituted $316(52.2 \%)$ and untrained comprised 289 $(47.8 \%)$. The investigation, therefore, proceeded with the other prerequisites of the MGA.

The results of the PLS algorithm for LMS training groups are illustrated in Table II. As can be observed from the data, criteria of internal consistency reliability, composite reliability and AVE, were satisfactory. Similarly, the assessment of compositional invariance (MICOM) was conducted using a permutation test. Results of MICOM represented a problem in the analysis that Social Influence (SI) and Facilitating Condition (FC) scores were significantly different from one which did not support the partial measurement invariance. Since these two variables (SI, FC) composites differ regarding their composition across the groups, the researcher eliminated the construct that did not achieve compositional invariance from both groups as suggested by Hair et al. [16] and Henseler et al. [44].

TABLE II: THE MEASUREMENT MODEL ASSESSMENT FOR TRAINING
\begin{tabular}{|c|c|c|c|c|c|c|}
\hline & \multicolumn{3}{|c|}{ Training Group } & \multicolumn{3}{c|}{ Untrained Group } \\
\hline Construct & $\begin{array}{c}\text { CA > } \\
\mathbf{0 . 7}\end{array}$ & $\begin{array}{c}\text { CR }> \\
\mathbf{0 . 7}\end{array}$ & $\begin{array}{c}\text { AVE }> \\
\mathbf{0 . 5}\end{array}$ & $\begin{array}{c}\text { CA > } \\
\mathbf{0 . 7}\end{array}$ & $\begin{array}{c}\text { CR > } \\
\mathbf{0 . 7}\end{array}$ & $\begin{array}{c}\text { AVE > } \\
\mathbf{0 . 5}\end{array}$ \\
\hline $\begin{array}{c}\text { Actual Use } \\
\text { (AU) }\end{array}$ & 0.750 & 0.844 & 0.578 & 0.745 & 0.840 & 0.572 \\
\hline $\begin{array}{c}\text { Behavioural } \\
\text { Intention } \\
\text { (BI) }\end{array}$ & 0.902 & 0.945 & 0.810 & 0.915 & 0.947 & 0.817 \\
\hline $\begin{array}{c}\text { Performance } \\
\text { Expectancy } \\
\text { (PE) }\end{array}$ & 0.837 & 0.891 & 0.673 & 0.839 & 0.893 & 0.677 \\
\hline $\begin{array}{c}\text { Effort } \\
\text { Expectancy } \\
\text { (EE) }\end{array}$ & 0.913 & 0.939 & 0.794 & 0.874 & 0.914 & 0.726 \\
\hline $\begin{array}{c}\text { Instructional } \\
\text { Assessment } \\
\text { (IA) }\end{array}$ & 0.903 & 0.940 & 0.723 & 0.887 & 0.914 & 0.641 \\
\hline $\begin{array}{c}\text { Information } \\
\text { Quality (IQ) }\end{array}$ & 0.915 & 0.958 & 0.819 & 0.901 & 0.927 & 0.718 \\
\hline $\begin{array}{c}\text { System } \\
\text { Learnability } \\
\text { (SL) }\end{array}$ & 0.897 & 0.924 & 0.710 & 0.849 & 0.892 & 0.625 \\
\hline $\begin{array}{c}\text { System } \\
\text { Navigation } \\
\text { (SN) }\end{array}$ & 0.866 & 0.903 & 0.651 & 0.839 & 0.885 & 0.608 \\
\hline $\begin{array}{c}\text { Visual } \\
\text { Design (VD) }\end{array}$ & 0.918 & 0.936 & 0.711 & 0.909 & 0.931 & 0.693 \\
\hline $\begin{array}{c}\text { E-learning } \\
\text { System } \\
\text { Interactivity } \\
\text { (ESI) }\end{array}$ & 0.886 & 0.920 & 0.741 & 0.864 & 0.904 & 0.703 \\
\hline CA & & & & & \\
\hline
\end{tabular}

CA: Cronbach's alpha, CR: composite reliability, AVE: average variance extracted

The elements in the matrix diagonals, presented in Table IV, indicate the square roots of the average variance extracted. The diagonal bold values confirmed that all the AVEs are higher than any other correlation. Therefore, the discriminant validity of the constructs is established for both trained and untrained sub-samples.

TABLE III: FORNELL-LARCKER DISCRIMINANT VALIDITY FOR EXPERIENCE

\begin{tabular}{|c|c|c|c|c|c|c|c|c|c|c|c|c|}
\hline \multicolumn{13}{|c|}{ Lower Experience Students } \\
\hline & $\mathbf{A U}$ & BI & EE & FC & IQ & IA & ESI & SL & SN & PE & SI & VD \\
\hline $\mathbf{A U}$ & 0.833 & & & & & & & & & & & \\
\hline BI & 0.409 & 0.908 & & & & & & & & & & \\
\hline $\mathbf{E E}$ & 0.379 & 0.633 & 0.890 & & & & & & & & & \\
\hline FC & 0.581 & 0.528 & 0.632 & 0.748 & & & & & & & & \\
\hline IQ & 0.455 & 0.665 & 0.599 & 0.600 & 0.881 & & & & & & & \\
\hline ESI & 0.377 & 0.574 & 0.463 & 0.520 & 0.757 & 0.765 & 0.881 & & & & & \\
\hline SL & 0.479 & 0.653 & 0.724 & 0.676 & 0.737 & 0.701 & 0.587 & 0.844 & & & & \\
\hline SN & 0.412 & 0.649 & 0.612 & 0.647 & 0.656 & 0.716 & 0.668 & 0.709 & 0.791 & & & \\
\hline $\mathbf{P E}$ & 0.420 & 0.776 & 0.604 & 0.533 & 0.669 & 0.553 & 0.652 & 0.631 & 0.622 & 0.858 & & \\
\hline SI & 0.720 & 0.394 & 0.329 & 0.520 & 0.578 & 0.492 & 0.468 & 0.478 & 0.381 & 0.448 & 0.798 & \\
\hline VD & 0.407 & 0.319 & 0.327 & 0.590 & 0.611 & 0.659 & 0.616 & 0.653 & 0.670 & 0.371 & 0.536 & 0.848 \\
\hline \multicolumn{13}{|c|}{ Higher Experience Students } \\
\hline$\overline{\mathbf{A U}}$ & 0.845 & & & & & & & & & & & \\
\hline BI & 0.608 & 0.901 & & & & & & & & & & \\
\hline $\mathbf{E E}$ & 0.474 & 0.484 & 0.855 & & & & & & & & & \\
\hline FC & 0.527 & 0.559 & 0.582 & 0.725 & & & & & & & & \\
\hline
\end{tabular}




\begin{tabular}{|l|l|l|l|l|l|l|l|l|l|l|l|l|}
\hline IQ & 0.434 & 0.404 & 0.442 & 0.547 & $\mathbf{0 . 8 7 9}$ & & & & & & & \\
\hline IA & 0.456 & 0.464 & 0.440 & 0.573 & 0.674 & $\mathbf{0 . 7 8 3}$ & & & & & & \\
\hline ESI & 0.364 & 0.525 & 0.346 & 0.465 & 0.528 & 0.611 & $\mathbf{0 . 8 3 5}$ & & & & & \\
\hline SL & 0.537 & 0.500 & 0.672 & 0.679 & 0.658 & 0.553 & 0.522 & $\mathbf{0 . 7 8 7}$ & & & & \\
\hline SN & 0.478 & 0.481 & 0.563 & 0.618 & 0.530 & 0.541 & 0.538 & 0.720 & $\mathbf{0 . 7 8 3}$ & & & \\
\hline PE & 0.567 & 0.700 & 0.457 & 0.516 & 0.532 & 0.511 & 0.465 & 0.504 & 0.447 & $\mathbf{0 . 7 9 9}$ & & \\
\hline SI & 0.539 & 0.532 & 0.424 & 0.563 & 0.474 & 0.466 & 0.385 & 0.486 & 0.453 & 0.545 & $\mathbf{0 . 7 7 9}$ & \\
\hline VD & 0.414 & 0.379 & 0.496 & 0.535 & 0.571 & 0.574 & 0.524 & 0.686 & 0.677 & 0.337 & 0.365 & $\mathbf{0 . 8 3 4}$ \\
\hline
\end{tabular}

TABLE IV: THE FORNELL-LARCKER DISCRIMINANT VALIDITY FOR TRAINING

\begin{tabular}{|c|c|c|c|c|c|c|c|c|c|c|}
\hline \multicolumn{11}{|c|}{ Trained Students } \\
\hline & $\mathrm{AU}$ & $\mathrm{BI}$ & $\mathrm{EE}$ & ESI & IA & IQ & $\mathrm{PE}$ & SL & SN & VD \\
\hline$\overline{\mathrm{AU}}$ & 0.760 & & & & & & & & & \\
\hline $\mathrm{BI}$ & 0.565 & 0.900 & & & & & & & & \\
\hline $\mathrm{EE}$ & 0.523 & 0.656 & 0.891 & & & & & & & \\
\hline ESI & 0.453 & 0.588 & 0.481 & 0.861 & & & & & & \\
\hline IA & 0.549 & 0.570 & 0.594 & 0.727 & 0.850 & & & & & \\
\hline IQ & 0.496 & 0.628 & 0.538 & 0.650 & 0.736 & 0.905 & & & & \\
\hline $\mathrm{PE}$ & 0.599 & 0.792 & 0.620 & 0.630 & 0.648 & 0.713 & 0.821 & & & \\
\hline SL & 0.592 & 0.647 & 0.792 & 0.640 & 0.731 & 0.701 & 0.657 & 0.842 & & \\
\hline SN & 0.549 & 0.606 & 0.706 & 0.639 & 0.688 & 0.653 & 0.633 & 0.750 & 0.807 & \\
\hline VD & 0.455 & 0.479 & 0.522 & 0.566 & 0.694 & 0.653 & 0.516 & 0.702 & 0.704 & 0.843 \\
\hline \multicolumn{11}{|c|}{ Untrained Students } \\
\hline & $\mathrm{AU}$ & BI & $\mathrm{EE}$ & ESI & IA & IQ & PE & SL & SN & VD \\
\hline$\overline{\mathrm{AU}}$ & 0.757 & & & & & & & & & \\
\hline $\mathrm{BI}$ & 0.577 & 0.904 & & & & & & & & \\
\hline $\mathrm{EE}$ & 0.453 & 0.493 & 0.852 & & & & & & & \\
\hline ESI & 0.323 & 0.479 & 0.340 & 0.839 & & & & & & \\
\hline IA & 0.442 & 0.472 & 0.487 & 0.620 & 0.800 & & & & & \\
\hline $\mathrm{IQ}$ & 0.436 & 0.429 & 0.520 & 0.477 & 0.568 & 0.847 & & & & \\
\hline$\overline{\mathrm{PE}}$ & 0.501 & 0.757 & 0.494 & 0.481 & 0.477 & 0.509 & 0.823 & & & \\
\hline SL & 0.506 & 0.511 & 0.705 & 0.486 & 0.569 & 0.678 & 0.529 & 0.791 & & \\
\hline $\mathrm{SN}$ & 0.469 & 0.467 & 0.545 & 0.545 & 0.591 & 0.575 & 0.450 & 0.717 & 0.780 & \\
\hline VD & 0.429 & 0.370 & 0.437 & 0.532 & 0.531 & 0.604 & 0.383 & 0.631 & 0.695 & 0.832 \\
\hline
\end{tabular}

\section{B. Structural Model Assessment}

Table $\mathrm{V}$ presented path coefficients for each group, the explained variance $\left(R^{2}\right)$ along with the test of differences between the sub-samples. Since the permutation test is nonparametric, two-tailed, more conservative, and recommended by researchers [15], [16], the researcher employed it in the analysis. Some relationships indicate a significant difference between the higher and lower users, evidenced by the p-value below 0.05 significant level. To start with, the relationship between behavioural intention and actual use is significantly different among higher experienced users $\left(\beta^{(1)}=0.383\right)$ versus those who are beginners $\left(\beta^{(2)}=0.046\right)$ with the path being significant in the higher experienced group but not in the beginners. Similarly, the effect of information quality on behavioural intention is significantly different between experienced students $\left(\beta^{(1)}=\right.$ $0.166)$ and beginner students $\left(\beta^{(2)}=0.299\right)$, with the path being significant in the experienced group but not in the beginner's category. Finally, the relationship between social influence and actual use is significantly $(p<0.10)$ different for experienced students $\left(\beta^{(1)}=0.234\right)$ versus less experienced users $\left(\beta^{(2)}=0.570\right)$. However, the relationship between social influence and actual use is significant for both advanced and novices' group. The other relationships of the model do not indicate a major difference between advanced and beginner groups.
TABLE V: THE MODERATING EFFECT FOR EXPERIENCE

\begin{tabular}{|c|c|c|c|c|c|}
\hline \multirow[t]{2}{*}{ Paths } & \multicolumn{2}{|c|}{$\begin{array}{c}\text { High } \\
\text { Experience }\end{array}$} & \multicolumn{2}{|c|}{$\begin{array}{c}\text { Low } \\
\text { Experience }\end{array}$} & \multirow{2}{*}{$\begin{array}{c}\text { Test } \\
\text { p-Values }\end{array}$} \\
\hline & $\beta$ & $\mathbf{R}^{2}$ & $\beta$ & $\mathbf{R}^{2}$ & \\
\hline BI $->$ AU & 0.383 & \multirow{3}{*}{0.447} & 0.046 & \multirow{3}{*}{0.559} & 0.018 \\
\hline FC $\rightarrow$ AU & 0.181 & & 0.258 & & 0.610 \\
\hline SI -> AU & 0.234 & & 0.570 & & 0.018 \\
\hline EE -> BI & 0.108 & \multirow{11}{*}{0.582} & 0.039 & \multirow{11}{*}{0.66} & 0.686 \\
\hline ESI -> BI & 0.227 & & 0.040 & & 0.330 \\
\hline FC $\rightarrow>$ BI & 0.158 & & 0.067 & & 0.502 \\
\hline IA -> BI & -0.021 & & -0.164 & & 0.377 \\
\hline IQ -> BI & -0.166 & & 0.296 & & 0.003 \\
\hline PE -> BI & 0.489 & & 0.415 & & 0.628 \\
\hline SI -> BI & 0.120 & & 0.032 & & 0.438 \\
\hline SL -> BI & -0.011 & & 0.113 & & 0.613 \\
\hline SN -> BI & 0.029 & & 0.300 & & 0.183 \\
\hline VD -> BI & 0.008 & & -0.276 & & 0.080 \\
\hline VD -> BI & 0.008 & & -0.276 & & 0.080 \\
\hline EE -> PE & 0.205 & \multirow{7}{*}{0.392} & 0.143 & \multirow{7}{*}{0.568} & 0.731 \\
\hline IQ -> PE & 0.244 & & 0.310 & & 0.687 \\
\hline ESI -> PE & 0.176 & & 0.403 & & 0.098 \\
\hline IA $->$ PE & 0.174 & & -0.202 & & 0.059 \\
\hline VD -> PE & -0.238 & & -0.260 & & 0.901 \\
\hline SL $>$ PE & 0.114 & & 0.190 & & 0.778 \\
\hline SN -> PE & 0.088 & & 0.228 & & 0.550 \\
\hline IA $->$ EE & 0.135 & \multirow{6}{*}{0.452} & -0.141 & \multirow{6}{*}{0.558} & 0.114 \\
\hline ESI -> EE & -0.083 & & 0.073 & & 0.330 \\
\hline IQ -> EE & -0.060 & & 0.248 & & 0.114 \\
\hline SL $->$ EE & 0.579 & & 0.666 & & 0.697 \\
\hline SN -> EE & 0.102 & & 0.181 & & 0.698 \\
\hline VD -> EE & 0.034 & & -0.329 & & 0.046 \\
\hline
\end{tabular}


Table VI illustrates the path coefficients for each training categories, the explained variance $\left(R^{2}\right)$ along with the permutation $\mathrm{p}$-value for both groups. It can be seen from the data in Table VI that the only moderating effect of training is the association between the information quality and performance expectancy. These relationships were significant. Nonetheless, trained students exhibited higher perceptions ( $\beta=0.416$ ) of the LMS information quality and its effect on the system usefulness than did the untrained counterpart $(\beta=0.196)$.

TABLE VI: THE MODERATING EFFECT FOR TRAINING

\begin{tabular}{|c|c|c|c|c|c|}
\hline \multirow[t]{2}{*}{ Paths } & \multicolumn{2}{|c|}{ Trained Students } & \multicolumn{2}{|c|}{$\begin{array}{l}\text { Untrained } \\
\text { Students }\end{array}$} & \multirow{2}{*}{$\begin{array}{c}\text { Test } \\
\text { p-Values }\end{array}$} \\
\hline & $\beta$ & $\mathbf{R}^{2}$ & $\beta$ & $\mathbf{R}^{2}$ & \\
\hline $\mathbf{B I}->\mathbf{A U}$ & 0.565 & 0.318 & 0.577 & 0.331 & 0.843 \\
\hline EE -> BI & 0.255 & \multirow{8}{*}{0.674} & 0.104 & \multirow{8}{*}{0.601} & 0.089 \\
\hline ESI -> BI & 0.134 & & 0.102 & & 0.746 \\
\hline IA -> BI & -0.103 & & 0.047 & & 0.076 \\
\hline IQ -> BI & 0.075 & & -0.076 & & 0.088 \\
\hline PE -> BI & 0.550 & & 0.625 & & 0.376 \\
\hline SL $->$ BI & 0.029 & & 0.047 & & 0.879 \\
\hline SN $>$ BI & -0.002 & & 0.078 & & 0.407 \\
\hline VD -> BI & -0.010 & & -0.033 & & 0.785 \\
\hline EE -> PE & 0.275 & \multirow{7}{*}{0.611} & 0.211 & \multirow{7}{*}{0.385} & 0.514 \\
\hline ESI -> PE & 0.200 & & 0.246 & & 0.606 \\
\hline IA -> PE & 0.058 & & 0.076 & & 0.863 \\
\hline IQ -> PE & 0.417 & & 0.196 & & 0.043 \\
\hline SL -> PE & -0.030 & & 0.134 & & 0.209 \\
\hline SN -> PE & 0.092 & & 0.010 & & 0.477 \\
\hline VD -> PE & -0.098 & & -0.090 & & 0.940 \\
\hline ESI -> EE & -0.101 & \multirow{6}{*}{0.643} & -0.081 & \multirow{6}{*}{0.506} & 0.814 \\
\hline IA $>$ EE & 0.115 & & 0.149 & & 0.728 \\
\hline IQ -> EE & -0.038 & & 0.061 & & 0.315 \\
\hline SL -> EE & 0.698 & & 0.605 & & 0.368 \\
\hline SN -> EE & 0.236 & & 0.087 & & 0.150 \\
\hline VD -> EE & -0.131 & & -0.077 & & 0.601 \\
\hline
\end{tabular}

\section{DISCUSSION}

\section{A. Experience}

The permutation test, presented in Table $\mathrm{V}$, reveals that LMS experience moderated three relationships: $\mathrm{BI} \rightarrow \mathrm{AU}$, IQ -> BI and SI->AU. This is similar to the Ameen et al. [8] and Binyamin et al. [50] conclusion in which not much difference was found between students with low or high levels of LMS experience. Nonetheless, LMS experience has moderated the effect of BI on students usage behaviour of the LMS in Saudi Arabia. This is consistent with results obtained by Taylor \& Todd [27] where the path from intention to usage behaviour was stronger for experienced users than for inexperienced users. The results are also in line with the findings of Sun \& Zhang [13]. In contrast with UTAUT findings, the students with prior experience seem to be more motivated to use LMS than less experienced users [10]. The results also contradict the study of Venkatesh et al. [30] in which the behavioural intention effect on technology use was stronger with less experienced users. It may be that these participants benefitted more from the LMS, as PE->BI was stronger for experienced users than for the beginners, supporting previous findings of Tarhini, Hone, \& Liu [51]. Besides, the EE->PE was significant in the advanced group only, indicating a greater inclination to system ease of use and this might add further insight to the students affirmed the intention to use LMS. This finding is in compliance with the Venkatesh \& Bala [26]'s conclusion in which the influence of perceived ease of use on usefulness will be stronger with advanced users. Thus, with increasing experience, Saudi use of LMS appears to be more for pragmatic purposes, such as gains in efficiency and effectiveness. That eventually will reinforce the actual behaviour. Therefore, LMS experienced users utilize their prior experience to form their intentions so, the more experience students acquire in the use of LMS, the more the affirmation of the usage behaviour.

The experience also moderated the IQ -> BI relationship. It is an inverse relationship. This means that the quality of the content of the LMS, its relevancy, completeness and timeliness contents negatively impact the students' willingness to use the LMS. It is rather an unanticipated finding and it merits further exploration. The negative interaction of experience on the effect of IQ on BI could be interpreted such that, more experienced individuals possess stable perceptions about the LMS usefulness and ease of use irrespective of the LMS content. This then translated into affirmed intention to use the LMS. Another plausible explanation might be related to that highly experienced students might find that the information of LMS is overwhelming, discouraging them from using the system.

Finally, the relationship between social influence and actual use was moderated by experience. It is evident that the less experienced users of LMS tend to be more susceptible to referents' opinions and the effect did not attenuate with increased experience. The results in this investigation were consistent with those of other studies [10], [25] in which in the mandatory settings, social influence appears to be important only in the early stages of individual experience with the technology. A similar finding was demonstrated by Calisir, Altin Gumussoy, \& Bayram [52] who asserted that less experienced respondents showed high social influence toward the individuals' intention to use the system ERP system in Turkey. Besides, it was demonstrated that the social influence effect on perceived usefulness and behavioural intention was weaker with increased hands-on experience on the system [26]. Therefore, our result is expected in Saudi higher education as students comply with other expectations, especially in the early stages of experience where students' opinions are relatively illinformed.

Regarding the explained variance of the experience moderators, the results demonstrated that the shared variance in advanced group for $\mathrm{AU}, \mathrm{BI}, \mathrm{EE}, \mathrm{PE}$ is 0.447 $(45 \%), \quad 0.582(58 \%), 0.452(45 \%)$ and $0.392(39 \%)$ respectively. The less experienced student sample the explained variance for $\mathrm{AU}, \mathrm{BI}, \mathrm{EE}, \mathrm{PE}$ is 0.559 (56\%), $0.660(66 \%), 0.558(56 \%)$ and $0.568(57 \%)$ respectively. As it can be seen, the proposed model explained more variance in the less experienced category. This is in agreement with a recent study in the Saudi context, where lower-level experienced usage behaviours were well predicted by the independent variables [50]. The results are in parallel with the semnial study of Taylor \& Todd [27] which demonstrated that the inexperienced users' intentions were better predicted by the antecedent variables in the model than were the intentions of experienced users. This indicates a better model fit for younger students in the dependent variables AU, BI, EE, PE. A plausible explanation for this 
difference might be the fact that our study sample comprises students from newly established universities where LMS has been recently introduced, so the students might have been more encouraged to use the system. Changes of perceptions are anticipated as the individuals gained more experience and knowledge about the system [41].

\section{B. Training}

The results of the permutation algorithm, presented in Table VI, established that LMS training moderates a single relationship: the information quality influence on performance expectancy. The lack of support in other relationships might be explained by the fact that around half of the participants in the study sample did not receive any training in the use of the LMS. This was supported in the previous studies in which a number of researchers acknowledged the lack of training in the use of LMS in Saudi universities [12], [32], [33]. However, significant differences in the group-specific path coefficients were noted. The trained students exhibited higher perceptions of the LMS information quality and its effect on the system usefulness than did their untrained counterparts. These relationships were significant in both groups. This means that trained students found information in the LMS platform to be accurate, relevant, timely, sufficient and complete. Those attributes subsequently contribute to the system usefulness more than the effect on the untrained students. These findings are unsurprising as the training given about the use of LMS seems not only to improve the students' technical skills but also the related pedagogical knowledge (i.e. LMS content). This is consistent with previous research [41] in which some relationships were intensified over the course of the training.

Regarding the model's explanatory power. Overall, the model was able to account for a substantial part of the variances in students' acceptance decisions: $67 \%$ with training and $60 \%$ without training. In a comparison of the $R^{2}$ values of performance expectancy and effort expectancy, the trained model explained $61 \%$ of the variances for performance expectancy and 64\% for effort expectancy. Whereas there was $39 \%$ for the variance of performance expectancy and $51 \%$ for the variance for effort expectancy in the untrained model. This is in line with the $\mathrm{Hu}$ et al. [41] finding in which the model's explanatory power appeared to increase over the course of the training. Clearly, the model's explained variances appeared to increase with the training, indicating the important moderation effect of training in the students' acceptance and use of LMS in Saudi higher education.

\section{CONCLUSION}

This study investigated the impact of moderating effect on the students' use of LMS in Saudi higher education. Specifically, experience and training received variables were posited to affect the extended UTAUT model relationships. The findings revealed three relationships (BI -> AU, IQ -> $\mathrm{BI}$ and SI->AU) were impacted by experience whereas only IQ -> PE was influenced by the training given to the students. It can be deduced that the two demographic moderators have little impact on the students' use of LMS in
Saudi higher education. Still, the study substantiates the students' demographic differences regarding path significance and intensity. Lecturers and administrators should pay more consideration to recognized differences between the groups. It is important to note that less experienced and trained students place more emphasis on the determinants of intention and usage behaviour, evidenced by the explained variance of each categories. University policymakers are expected to benefit from this research as to find an effective approach for e-learning system acceptance in an academic setting and eliminate any impediments to its implementation. That in turn will improve their future strategic initiatives of technology implementation considering the different groups of students preferences and the usability factors relevant to their use. Thus, a key policy priority should therefore be to enhance the strategic plan for e-learning systems implementation at universities.

Before drawing definitive conclusions from these results, it is important to consider the study's limitations. Firstly, this cross-sectional study analysed data at a specific point in time. Several lines of evidence suggest that longitudinal research is recommended in which the same students are observed over the study period. This would appreciate the time and the dynamics of students' usage behaviour. The students' perceptions and preferences about technology may change as they gain more experience in LMS so a continuous improvement of LMS is advised to address any issues and shortfalls. Secondly, apart from the intra-cultural context limitations, the scope of this study was limited to higher education in Saudi Arabia so the generalisation at a crosscultural level is undetermined. Thus, it is desirable to include geographically distributed universities around the Gulf region which might improve the generalizability of our research outcomes. Thirdly, the current research targeted students' experience of the Blackboard system. So an issue that was not addressed in this study was whether other platforms e.g. Moodle and Desire2Learn would lead to similar conclusions. Students have different motivation and experience in using different types of platforms, thus, this would be a fruitful area for further work.

\section{CONFLICT OF INTEREST}

The authors declare no conflict of interest.

\section{AUTHOR CONTRIBUTIONS}

All authors have contributed to this work. Ahmed Alshehri conducted the research; Malcolm and Sally have proofread the paper and provided valuable feedback. All authors had approved the final version.

\section{ACKNOWLEDGEMENT}

I would like to express my very great appreciation to Albaha University and the Ministry of Education in Saudi Arabia for the financial support of the study.

\section{REFERENCES}

[1] R. Walker, J. Voce, E. Swift, A. Jebar, M. Jenkins, and P. Vincent, 2016 Survey of Technology Enhanced Learning For Higher Education in the $U K, 2016$. 
[2] D. Walker, J. Lindner, T. P. Murphrey, and K. Dooley, Learning Management System Usage: Perspectives from University Instructors, vol. 17, no. 2, pp. 41-50, 2016.

[3] W. Watson and S. L. Watson, "An argument for clarity: What are learning management systems, what are they not, and what should they become?" TechTrends, vol. 51, no. 2, pp. 28-34, 2007.

[4] A. Aldiab, H. Chowdhury, A. Kootsookos, F. Alam, and H. Allhibi, "Utilization of Learning Management Systems (LMSs) in higher education system: A case review for Saudi Arabia," Energy Procedia, vol. 160, pp. 731-737, 2019.

[5] L. Y. Chaw and C. M. Tang, "What makes learning managemen systems effective for learning?" J. Educ. Technol. Syst., p. $004723951879582,2018$.

[6] E. Straub, "Understanding technology adoption: Theory and future directions for informal learning," Rev. Educ. Res., vol. 79, no. 2, pp. 625-649, Jun. 2009.

[7] S. A. Salloum and K. Shaalan, "Factors affecting students' acceptance of e-learning system in higher education using UTAUT and structural equation modeling approaches," in Proc. the International Conference on Advanced Intelligent Systems and Informatics, 2019, pp. 469-480.

[8] N. Ameen, R. Willis, M. N. Abdullah, and M. Shah, "Towards the successful integration of e-learning systems in higher education in Iraq: A student perspective," Br. J. Educ. Technol., vol. 50, no. 3, pp 1434-1446, 2019.

[9] A. Alshehri, M. Rutter, and S. Smith, "An implementation of the UTAUT model for understanding students' perceptions of learning management systems: A study within tertiary institutions in saud arabia," Int. J. Distance Educ. Technol., vol. 17, no. 3, p. 24, 2019.

[10] V. Venkatesh, M. G. Morris, G. B. Davis, and F. D. Davis, "User acceptance of information technology: Toward a unified view," MIS $Q$. , vol. 27, no. 3, pp. 425-478, 2003.

[11] A. Burton-Jones and G. S. Hubona, "The mediation of externa variables in the technology acceptance model," Inf. Manag., vol. 43 no. 6, pp. 706-717, 2006.

[12] M. J. Asiri, R. B. Mahmud, K. A. Bakar, and A. F. B. M. Ayub "Factors influencing the use of learning management system in Saudi Arabian higher education: A theoretical framework," High. Educ. Stud., vol. 2, no. 2, p. 125, May 2012

[13] H. Sun and P. Zhang, "The role of moderating factors in user technology acceptance," Int. J. Hum. Comput. Stud., vol. 64, no. 2, pp 53-78, Feb. 2006.

[14] J. Henseler and G. Fassott, "Testing moderating effects in PLS Path models: An illustration of available procedures," Handb. Partial Least Squares, pp. 713-735, 2010

[15] L. Matthews, Applying Multigroup Analysis in PLS-SEM: A Step-byStep Process, H. Latan and R. Noonan, Eds. Cham: Springer International Publishing, 2017, pp. 219-243.

[16] J. F. Hair Jr, M. Sarstedt, C. M. Ringle, and S. P. Gudergan, Advanced Issues in Partial Least Squares Structural Equation Modeling, 2018.

[17] J. Hair, G. T. Hult, C. Ringle, and M. Sarstedt, A Primer on Partial Least Squares Structural Equation Modeling ( PLS-SEM ), 2nd ed. Thousand Oaks : SAGE, 2017.

[18] H. Holden and R. Rada, "Understanding the influence of perceived usability and technology self-efficacy on teachers' technology acceptance," J. Res. Technol. Educ., vol. 43, no. 4, pp. 343-367, 2011.

[19] P. Zaharias and A. Poylymenakou, "Developing a usability evaluation method for e-learning applications: Beyond functional usability," Int. J. Hum. Comput. Interact., vol. 25, no. 1, pp. 75-98, Jan. 2009.

[20] A. Oztekin, Z. J. Kong, and O. Uysal, "UseLearn: A novel checklist and usability evaluation method for eLearning systems by criticality metric analysis," Int. J. Ind. Ergon., vol. 40, no. 4, pp. 455-469, 2010.

[21] K. A. Pituch and Y. kuei Lee, "The influence of system characteristics on e-learning use," Comput. Educ., vol. 47, no. 2, pp. 222-244, 2006.

[22] S. Binyamin, M. Rutter, and S. Smith, "Extending the technology acceptance model to understand students' use of learning managemen systems in Saudi higher education," Int. J. Emerg. Technol. Learn., vol. 14, no. 3, pp. 4-21, 2019.

[23] A. Alshehri, M. Rutter, and S. Smith, "Assessing the relative importance of an e-learning system's usability design characteristics based on students' preferences," Eur. J. Educ. Res., vol. 8, no. 3, pp. 839-855, 2019.

[24] S. Binyamin, M. Rutter, S. Smith, and A. Alshehri, "The Influence of usability attributes on students' use of learning management systems: A theoretical framework," in Proc. Edulearn19, 2019, vol. 1, pp. 10608-10619.

[25] V. Venkatesh and M. G. Morris, "Why don't men ever stop to ask for directions? Gender, social influence, and their role in technology acceptance and usage behavior," MIS Q., vol. 24, no. 1, pp. 115-139, 2000
[26] V. Venkatesh and H. Bala, "Technology acceptance model 3 and a research agenda on interventions," Decis. Sci., vol. 39, no. 2, pp. 273 $315,2008$.

[27] S. Taylor and P. A. Todd, "Assessing IT usage: The role of prior experience,” Manag. Inf. Syst. Q., vol. 19, no. 4, pp. 561-570, Dec. 1995.

[28] H.-L. Liao and H.-P. Lu, "The role of experience and innovation characteristics in the adoption and continued use of e-learning websites," Comput. Educ., vol. 51, no. 4, pp. 1405-1416, 2008.

[29] M. Zhang, Y. Liu, W. Yan, and Y. Zhang, "Users' continuance intention of virtual learning community services: The moderating role of usage experience," Interact. Learn. Environ., vol. 25, no. 6, pp 685-703, 2017.

[30] V. Venkatesh, J. Y. L. Thong, and X. Xu, "Consumer acceptance and use of information technology: Extending the unified theory of acceptance and use of technology," MIS Q., vol. 36, no. 1, pp. 157178, 2012.

[31] H. M. Selim, "Critical success factors for e-learning acceptance: Confirmatory factor models," Comput. Educ., vol. 49, no. 2, pp. 396413, Sep. 2007.

[32] A. E. S. Al-Alwani, "Barriers to effective use of information technology in science education,"in Proc. 2010 Int. Conf. Enterp. Inf. Syst. Web Technol. EISWT 2010, pp. 42-49, 2010.

[33] E. Al Mulhim, "The barriers to the use of ICT in teaching in Saudi Arabia: A review of literature," Univers. J. Educ. Res., vol. 2, no. 6 , pp. 487-493, 2014

[34] K. A. Al-Busaidi and H. Al-Shihi, "Key factors to instructors' satisfaction of learning management systems in blended learning," $J$ Comput. High. Educ., vol. 24, no. 1, pp. 18-39, 2012.

[35] C. A. Higgins and D. R. Compeau, "Computer self-efficacy: Development of a measure and initial test," MIS Q., vol. 19, no. 2, pp. 189-211, 1995.

[36] A. Quazi and M. Talukder, "Demographic determinants of adoption of technological innovation," J. Comput. Inf. Syst., vol. 51, no. 3, pp. 3846, 2011

[37] M. Igbaria, N. Zinatelli, P. Cragg, and A. L. M. Cavaye, "Personal computing acceptance factors in small firms: A structural equation model," MIS Q., vol. 21, no. 3, pp. 279-305, 1997.

[38] K. Rouibah, H. I. Hamdy, and M. Z. Al-Enezi, "Effect of management support, training, and user involvement on system usage and satisfaction in Kuwait," Ind. Manag. Data Syst., vol. 109, no. 3, pp. 338-356, 2009.

[39] P. Rogers, "Barriers to adopting emerging technologies in education," J. Educ. Comput. Res., vol. 22, no. 4, pp. 455-472, Jun. 2000.

[40] F. D. Davis, "Perceived usefulness, perceived ease of use, and user acceptance of information technology," MIS $Q$., vol. 13, no. 3, pp. 319-340, 1989.

[41] P. J.-H. Hu, T. H. K. Clark, and W. W. Ma, "Examining technology acceptance by school teachers: A longitudinal study," Inf. Manag., vol. 41 , no. 2, pp. 227-241, 2003.

[42] A. Bryman and E. Bell, Business Research Methods, USA: Oxford University Press, 2015

[43] C. M. Ring, S. Wende, and J. Becker, "Smart PLS 3," Boenningstedt SmartPLS GmbH, 2015

[44] J. Henseler, C. M. Ringle, and M. Sarstedt, "Testing measurement invariance of composites using partial least squares," Int. Mark. Rev., vol. 33, no. 3, pp. 405-431, May 2016.

[45] M. Sarstedt, C. Ringle, and J. F. Hair, Partial Least Squares Structural Equation Modeling, 2017.

[46] J. Hair, W. C. Black, B. J. Babin, and R. E. Anderson, Multivariate Data Analysis, 7th ed. Pearson Education Limited, 2014.

[47] R. B. Kline, Principles and Practice of Structural Equation Modeling, 4th ed. New York, NY, US: Guilford Press, 2016

[48] J. Hair, J. Risher, M. Sarstedt, and C. Ringle, "When to use and how to report the results of PLS-SEM," Eur. Bus. Rev., vol. 31, no. 1, pp. 2-24, Jan. 2019

[49] C. Fornell and D. F. Larcker, "Evaluating structural equation models with unobservable variables and measurement error," J. Mark. Res. vol. 18, no. 1, pp. 39-50, 1981.

[50] S. Binyamin, M. Rutter, and S. Smith, "The moderating effect of education and experience on the use of learning management systems," in Proc. the 2019 8th International Conference on Educational and Information Technology, 2019, pp. 293-300.

[51] A. Tarhini, K. Hone, and X. Liu, "The effects of individual differences on e-learning users' behaviour in developing countries: A structural equation model," Comput. Human Behav., vol. 41, pp. 153 163, Dec. 2014.

[52] F. Calisir, C. Altin Gumussoy, and A. Bayram, "Predicting the behavioral intention to use enterprise resource planning systems: An 
exploratory extension of the technology acceptance model," Manag. Res. News, vol. 32, no. 7, pp. 597-613, 2009.

Copyright (C) 2020 by the authors. This is an open access article distributed under the Creative Commons Attribution License which permits unrestricted use, distribution, and reproduction in any medium, provided the original work is properly cited (CC BY 4.0).

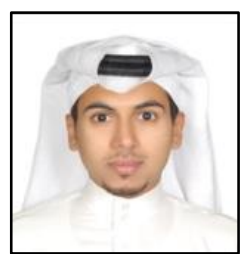

Ahmed Alshehri is a lecturer within the School of Computer Science and Information Technology at Albaha University, Saudi Arabia. $\mathrm{He}$ is also research student at Edinburgh Napier University. He has over 7 years of experience in project management, business continuity for IT services as well as various responsibilities in academia. $\mathrm{Mr}$ Alshehri graduated with a master's degree in Information Technology from the University of Western Australia (2011) and a bachelor's degree in Education, majoring Computer Science from King Khalid University (2007). His primary research interests include issues related to IS/IT adoption and implementation, human computer interaction, usability and e-learning.

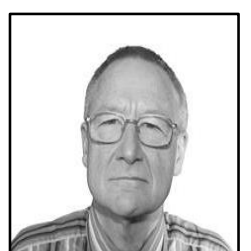

Malcolm J. Rutter trained as a communications engineer. His research experience started with his $\mathrm{PhD}$ in adaptive digital filtering. In the $\mathrm{PhD}$, Dr. Rutter was working on mathematical algorithms, of the sort that are nowadays found inside integrated circuits in applications such as mobile phones and sea divers' communication equipment. In Napier, he worked with optics projects. He mainly worked on fibre-optics for communications, and the use of passive infra-red detection for identifying people by their gait. In the School of computing, Dr. Rutter has done a lo of teaching in the field of HCI, which interests him greatly, and web design. $\mathrm{He}$ has published on the topic of student communications in education, which combines his interests in HCI, education and communication. More recently he has become involved in evaluating e-government, involving his interests in web design and HCI

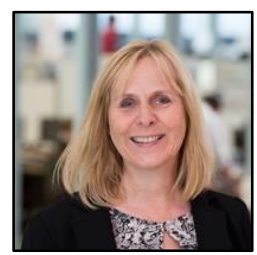

Sally Smith has an MA in mathematics from Aberdeen University, an MSc in computer science from City University, London and a DBA from Edinburgh Napier University. She is the dean of Computing at Edinburgh Napier University and project director of e-placement, Scotland. Prior to joining academia in 1992, she was a software engineer in the telecoms industry. She is also the director of the Computing Education Research Centre and her research interests are digital skills development and graduate employability. Prof. Smith is a Fellow of the British Computer Society and a Principal Fellow of the Higher Education Academy. 